\title{
Spatial variation of submarine groundwater discharge (SGD) and nutrient fluxes across a 125-km coastal area spanning variable hydroclimatic conditions: south Texas estuaries
}

DORINA MURGULET AND CODY LOPEZ

Texas A\&M University-Corpus Christi

Presenting Author: murguletd@yahoo.com

To determine how SGD and associated nutrient fluxes vary across estuaries with spatially different climatic and hydrologic conditions, this study investigated three south Texas estuaries encompassing $\sim 125-\mathrm{km}$, over four seasons. Using radon [ $\left.{ }^{222} \mathrm{Rn}\right]$, radium $\left[{ }^{226} \mathrm{Ra},{ }^{224} \mathrm{Ra}\right.$, and ${ }^{223} \mathrm{Ra}$ ] mass balance models, higher total SGD (fresh + saline) inputs were estimated for Nueces estuary (average $[\bar{x}]$ Nueces Bay and Corpus Christi Bay: 109 and $107 \mathrm{~cm} \mathrm{~d}^{-1}$, respectively), an area with substrates disturbed by anthropogenic activities and numerous growth faults, in the wetter climate region. The lowest rates occurred in the Upper Laguna Madre estuary ( $\bar{x}$ Laguna Madre and Baffin Bay 19 and $15 \mathrm{~cm} \mathrm{~d}^{-1}$, respectively), the area with the driest climate. Although located in the area with wettest climate, Aransas Bay

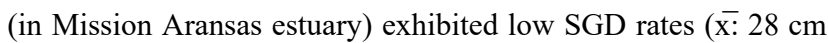
$\mathrm{d}^{-1}$ ). In the Upper Laguna Madre and Aransas Estuaries the total and saline estimates were in closer agreement, implying that saline SGD was more significant over short time scales. Porewater nutrient concentrations varied across the investigated systems and ultimately influenced the solute fluxes when compared to advective SGD. Significant inputs of SGD-derived nitrate occurred in Oso and Baffin bays ( $\overline{\mathrm{x}}$ : $65.6^{*} 103$ and5.3*10 ${ }^{3}$ $\mu \mathrm{mol} / \mathrm{m}^{2} /$ day, respectively). All other locations, except for Nueces Bay, exhibited average nitrate fluxes lower than $1 * 10^{3}$ $\mu \mathrm{mol} / \mathrm{m}^{2} /$ day. Average rates in Nueces Bay were $1.2 * 10^{3}$ $\mu \mathrm{mol} / \mathrm{m}^{2} /$ day. Nitrite fluxes show a similar trend to nitrate but were much lower. The most elevated ammonium fluxes occurred

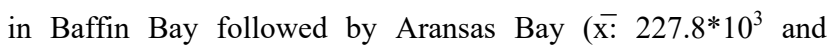
$96.3 * 10^{3} \mu \mathrm{mol} / \mathrm{m}^{2} /$ day, respectively), where seawater recirculation was more predominant. Fluxes for all other locations were lower by one order of magnitude than Baffin Bay and about three times lower than Aransas Bay. Total organic carbon (TOC) fluxes had a similar pattern to surface- and porewater TOC concentrations, which increase across the north to south climatic gradient; fluxe rates in Baffin Bay were almost twice higher in Aransas Bay ( $\overline{\mathrm{x}}$ : $529.1 * 10^{3}$ and $290.1 * 10^{3}$ $\mu \mathrm{mol} / \mathrm{m}^{2} / \mathrm{d}$, respectively). This study shows substantial SGD (forms/magnitudes) variability across a $125-\mathrm{km}$ coastline that is not predictably related to climate conditions, which has significant implications for coastal biogeochemical budgets. 